The International Journal of Indian Psychology: Volume: 01 | Issue: 04 No. 2 | ISSN 2348-5396

\title{
The Age Differences in Training of the Holistic Living Life Style.
}

\author{
Nilaben M. Borad*
}

\begin{abstract}
In the present ties individuals are suffering from various tensions and frustrations. To avoid this, experts are recommending the Holistic Life Style. This life style suggests living the life wholly or perfectly. That means the individual should lead the life completely, not only physically, but mentally and spiritually also. If proper knowledge is given the individual can easily lead Holistic living. In the present study the attempt is made in this direction. All individuals cannot be same in leading the Holistic life style. There would bind to be some differences due to the age. Thus the problem of the study is "The Age differences in Training of the Holistic Living Life Style" For the sample 50 students $10^{\text {th }}$ std. and the 50 students of college were selected randomly. For giving information about the Holistic Living Life Style the special material was prepared. The nature and the diseases due to lac of Holistic Living was mentioned. Different treatments were also discussed. The questionnaire was prepared for this purpose and was used as a tool for the research. The percentage and the t-test were found out. The result showed that there are differences between high school students and college students.

"The Age differences in Training of the Holistic Living life style."
\end{abstract}

The present life is a fast life. The individual has no time to look after the health. specially mental health. Many a times he suffers from the frustration and tension. To avoid this, experts suggest the holistic style of living. .That means the individual should lead the life completely, not only physically, but mentally and spiritually also. All individuals cannot be same in leading the Holistic life style. There would bind to be some differences due to the age. The individuals of younger age may not believe in holistic life style, but the persons of older age may like to follow the holistic living.

*Associated Professor, MahilaArts and Commerce College, Veraval. Gujarat 
The International Journal of Indian Psychology: Volume: 01 | Issue: 04 No. 2 | ISSN 2348-5396

The present researcher found it interesting to find out the age differences in racticising Holistic life style. Thus the problem of the study is "The Age differences in Training of the Holistic Living life style."

The researcher is of the opinion that if the proper training is given, even the younger generation will also take interest in the holistic living. The advantages of this kind of living should be discussed with the youths and thus their attitude should be made positive for the holistic way of life. The training is required for the youths, because their minds are like a clean slate and whatever information is given to them, it is received immediately.

In the present study the proper information is given to youth about the holistic living. And the attempt is made to measure the amount of the information they have grasped.

\section{METHODOLOGY}

\section{Problem :}

"The Age differences in Training of the Holistic Living life style."

\section{Objectives:}

1. To study the nature of Holistic living.

2. To prepare the questionnaire related to the Holistic living .

3. To find out the age differences in the training.

\section{Hypothesis:}

There are no age differences in training of the holistic living life style.

\section{Sample:}

The sample was consisted of 100 students. 50 from the $10^{\text {th }}$ class and 50 from the college. In each group 25 were males and 25 were females. They were from the Rajkot city. They were selected randomly. To bring the age differences $10^{\text {th }}$ class and the third year of the college students were taken.

\section{Tool:}

The specially prepared questionnaire was used as a tool.12 questions pertaining to the nature of the Holistic Living was framed.Firstly about 20 questions were prepared,After that they were presented to the experts .After their suggestions, finally 12 questions were selected. Three options were given as an answer to each question.The respondent had to select any one of them.1
(C) 2014 www.ijip.in
July-September 2014
$66 \mid \mathrm{P}$ a g e 
The International Journal of Indian Psychology: Volume: 01 | Issue: 04 No. 2 | ISSN 2348-5396

mark was given to correct answer, while 0 mark was assigned to the wrong answer.The questionnaire is given in the Appendix.

\section{Procedure:}

To give the training of Holistic Living, the primary information was given to the students. The information described the nature and importance of the holistic living. The various methods of the treatment were also described. The advantages of the Holistic Healing were also made clear to the students. This information was read before students.

After reading the information, the questionnaire based on it was given to the students. They were asked to choose any one option out of the three.

\section{RESULT AND DISCUSSION}

Firstly t-test was found out between the male students. The attempt was made to know whether age differences exist between the male students of 10th class and the third year students of the college. The details are given below:

\section{Table 1 showing age differences between male students in training.}

\begin{tabular}{|c|c|c|c|c|}
\hline Class & $\mathrm{N}$ & Mean & SD & $\mathrm{t}$ \\
\hline $10^{\text {th }}$ & 25 & 7.72 & 1.76 & \multirow{2}{*}{$4.1^{*}$} \\
\hline College & 25 & 6.00 & 1.20 & \\
\hline
\end{tabular}

*Significant at 0.01 level.

Table shows that there is difference between $10^{\text {th }}$ standard and college student score of means are 7.72 and 6.00 and calculated value is 4.1 and table value of $\mathrm{t}$ is $2.66 \mathrm{Fordf}=48$. So calculated $t$ value is more than $t$ table value, so it is significant at 0.01 level.

The male students of the 10th class have shown better performance than the college students. 
The International Journal of Indian Psychology: Volume: 01 | Issue: 04 No. 2 | ISSN 2348-5396

Graph No.1 showing age differences in males

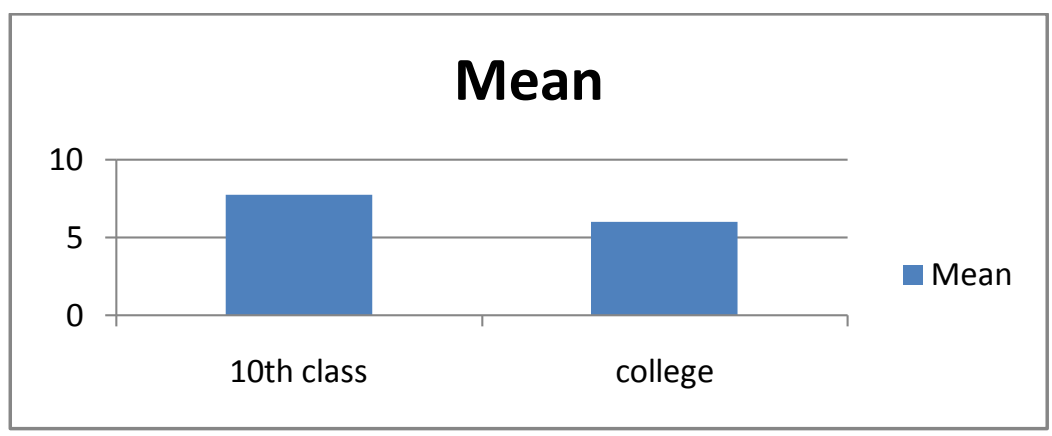

The t-test was also found out between the female students. To know whether age differences exist between the female students of 10th Class and the third year students of the college. The details are given below:

Table2. Showing age differences between female students in training.

\begin{tabular}{|c|c|c|c|c|}
\hline Class & $\mathrm{N}$ & Mean & SD & T \\
\hline $10^{\text {th }}$ & 25 & 4.72 & 1.86 & $2.54^{*}$ \\
\hline College & 25 & 6.00 & 2.00 \\
\hline
\end{tabular}

Significant at 0.05 levels.

Table shows that there is difference between $10^{\text {th }}$ standard and college student score of means are 4.72 and 6.00 and calculated value is 2.00 and table value of $t$ is 2.64 For $\mathrm{df}=48$. So calculated $t$ value is more than $t$ table value, so it is significant at 0.05 level.

The female students of the college have shown better performance than the students of the $10^{\text {th }}$. class.

\section{Graph No.2 showing age differences in females}

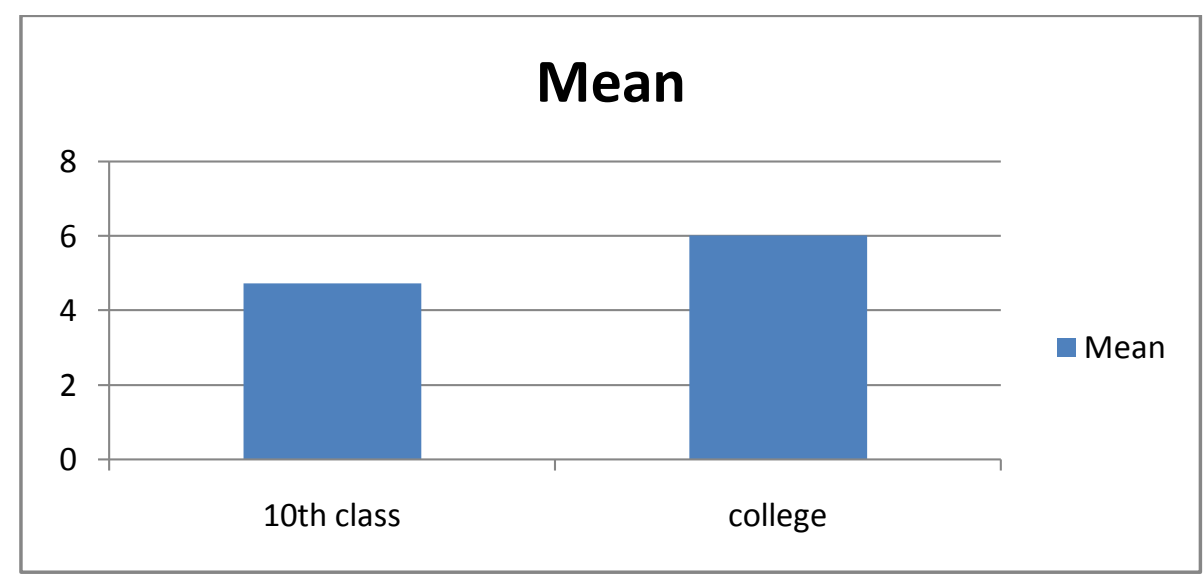




\section{Appendix}

The questionnaire on Holistic Living

You have to select any one option which you think best from the answers given with each question. Take As much time as you wants.

Q.1 What is meant by Holistic Living?

(a) To live comfortably.

(b)Not to live healthy life

(c) only physically, but mentally and spiritually also.

Q.2 What is meant by Holistic ?
(a)Universal
(b) Complete
(c)Whole.

Q.3 What type of life most of the people live ?
(a) Complete
(b) One sided
(c) Many sided.

Q.4 In whom the Holistic Living believe ?
(a) In God
(b) In Saints
(c) In counselor.

Q.5 How many therapies are there ?
(a)Two
(b)Three
(c) Four.

Q.6 Which therapy is popular connected with the psychology?
(a)Acupuncture
(b)Acupressure
(c)Reiki.

Q.7. What is gained by the therapy?
(a)Less quarrels
(b)Good health and peace
(c)Good relationships

Q.8. What can be removed by the therapy?
(a)Negative thoughts
(b)Bad thoughts
(c)Violent thoughts.

Q.9. What is meant by Tea and Chee in Chinese ?
(a)To listen the suffering of the individual
(b)To share and care (c)To provideguidance and counseling.

Q.10 By what name the Holistic healer is known?
(a)Psychologist
(b)Doctor
(c) Therapist

Q.11 Which medicine the psychiatrist gives to the patient?
(a)The tablets of energy
(b)Tranquilizers
(c)The tablets of vitamins

Q.12 In Holistic Living upon which factor the emphasis is given?
(a)Social matters
(b)Family matters
(c)Spiritual matter 
The International Journal of Indian Psychology: Volume: 01 | Issue: 04 No. 2 | ISSN 2348-5396

\section{REFERENCES}

1. Lama,Dalai \& others (2001).Souvenir of the Seminar on holistic and Integrated treatment. Nov.2001at Bangalore.

2. Horan,Paula (2000).Principles of Self-Healing.Full CirclePubications,New Delhi,2000.

3. Magazine.The Life Positive (2001).213,Sukhdevvihar,New Delhi. August,2001

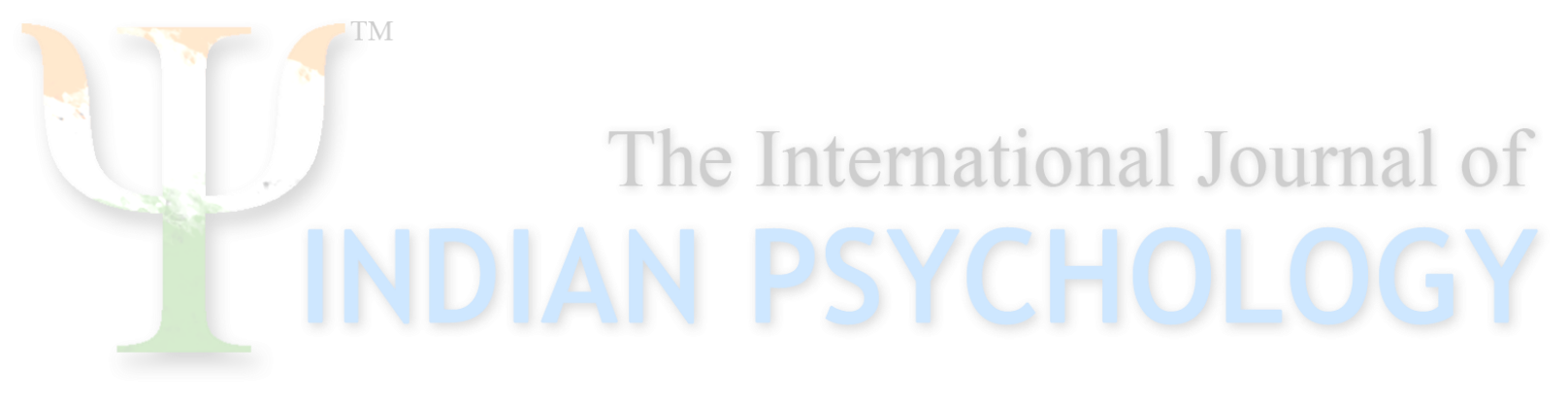

